\title{
Strategically Connecting a University to a Community
}

\author{
Michael R. Lovell ${ }^{1}$, Daniel Bergen², Maura Donovan ${ }^{3}$, and Rana Altenburg ${ }^{4}$ \\ ${ }^{1}$ Office of the President, Marquette University, ${ }^{2}$ Office of Civic Engagement, Marquette University, ${ }^{3}$ Office for \\ Corporate Engagement, Marquette University, ${ }^{4}$ Office for Public Affairs, Marquette University \\ Cite as: Lovell, M.R., Bergen, D., Donovan, M., \& Altenburg, R. (2019). Strategically Connecting a University to a \\ Community. Metropolitan Universities, 30(4), 72-78. DOI: 10.18060/38356
}

This is an open access article distributed under the terms of the Creative Commons Attribution License.

Editor: Valerie L. Holton, Ph.D.

\section{Introduction}

More than 450 years ago, Ignatius of Loyola and his colleagues founded the first of several Jesuit institutions in Sicily. They did this at a time when other higher education institutions existed, such as the University of Paris, where students were trained for professions in law, medicine, and the priesthood. What set the Jesuit colleges apart was that they were specifically created to train individuals who would improve the communities in which they lived, and not for a specific profession. Few responsibilities can be as invigorating, and at the same time overwhelming, as staying true to a tradition that dates back nearly 500 years, yet that is the challenge that Catholic, Jesuit universities accept when they carry on their mission of producing citizens who live their lives in service to others. At Marquette University, we've been striving to uphold this tradition for 138 years. We are constantly looking for new and innovative ways to help address some of Milwaukee's most pressing challenges and uniquely connect our talents and resources to benefit our community.

\section{Approach}

To further live our mission, Marquette has launched many new initiatives over the past five years that strategically connect our university to our community. In this paper, we will highlight three of these initiatives. The first relates to connecting the anchor institutions in our neighborhood through an effort called Near West Side Partners. The second discusses the creation of a centralized Office of Community Engagement that advances the development, support, and promotion of the research, teaching, and service partnerships between our campus and our community partners. The third initiative, our most recent enterprise, is our Office of Corporate Engagement and Partnerships. All three of these efforts follow through on Ignatius of Loyola's vision to serve others and collectively make a difference. 


\section{Near West Side Partners}

Near West Side Partners, Inc. (NWSP) is an economic development nonprofit serving seven neighborhoods just west of downtown Milwaukee. It started as a two-person conversation about community safety in the summer of 2014 between Harley-Davidson, Inc. CEO Keith Wandell and Marquette President Michael Lovell. It was prompted by a sudden spike in robberies around the university's campus and unprecedented violent crime in Harley-Davidson's parking lots, including a stray bullet that went through a conference room window during a business meeting. They agreed to take bold action to collaborate on how to best address community safety.

Their first action was to invite more than 20 corporate and nonprofit executives to a forum in October 2014 to discuss how they could improve their neighborhood. After the initial meeting, three other large organizations on Milwaukee's Near West Side made long-term leadership commitments: Aurora Health Care, MillerCoors, and Potawatomi Business Development Corporation. Together with Harley-Davidson, Inc. and Marquette, they became known as the anchor institutions. By January 2015, NWSP officially launched as a nonprofit, and it continues to serve more than 350 businesses, 94 nonprofits, 28,000 residents, and 29,000 employees.

While the anchors provided unprecedented levels of leadership and engagement to NWSP, it was critical to engage with residents and other community stakeholders to determine the strategic priorities for the neighborhood. NWSP learned through listening, which was the focus during the subsequent months. Based on community input, we agreed on four areas of focus: promoting economic development, improving and diversifying housing, unifying neighborhood identity and branding, and achieving greater safety for residents and businesses.

The effort gained significant momentum with an April 2015 announcement of multi-year commitments totaling more than $\$ 2$ million from the five anchor institutions to support NWSP's signature initiative: PARC, a highly effective, data-driven strategy to Promote Assets and Reduce Crime through the development of appropriate interventions targeting the four focus areas. Key components include a fully funded community prosecution unit dedicated to the Near West Side that includes an assistant district attorney, data analyst, and outreach worker who are embedded in the neighborhood. PARC coincided with a change at our university to further professionalize our public safety operations to becoming a fully sworn state-recognized university police department. In the first year of operation as Marquette University Police Department, we saw robberies decrease $28 \%$ and burglaries decrease 53\%. MUPD's success also dispersed crime in such a way that it helped reinforce Milwaukee Police Department's efforts to reduce overall crime in the Near West Side, resulting in similar double-digit decreases in robberies and burglaries outside the MUPD patrol zone.

These early wins in reducing crime provided the confidence for other law enforcement actions to be taken by the City of Milwaukee: one involved a court-ordered receivership for a multi-unit apartment building with excessive code violations and one resulted in court action to force the closure and ultimate demolition of a tobacco shop. The tobacco shop was the Near West Side's most problematic property, making it impossible to promote new development along its commercial corridor. In 2015, Milwaukee police responded to more than 230 calls for service at that property. After the city filed the lawsuit, the calls for service dropped by nearly $90 \%$. 
Eventually, the owner sold the property to the adjacent Penfield Children's Center, which plans to use that land to further develop its programs. In addition to the lawsuit, the power of the partnership was further demonstrated by the anchors working with the Wisconsin Legislature to close a state law loophole allowing tobacco shops to continue operating in spite of criminal activity or poor management.

The tobacco store effort gained the attention of Milwaukee Mayor Tom Barrett, who said in his 2017 State of the City address: "Working together, they were able to get the property declared a nuisance and changed state law to prevent problems like this in the future. This teamwork paid off when the property owner voluntarily agreed to close the shop. Talk about the power of partnerships. I want to thank the Near West Side Partners for rolling up their sleeves and committing themselves to our city."

We knew we were achieving our goals when our work received even wider external attention from organizations like the U.S. Department of Housing and Urban Development (HUD) and the International Town and Gown Association (ITGA). In 2018, HUD awarded a \$1.3 million Choice Neighborhoods Initiative grant to Near West Side Partners and Marquette to create a comprehensive community strategy focused on public housing options for senior citizens in the neighborhood. ITGA recognized the partnership with its 2017 Presidential Excellence Award, highlighting leadership that fosters beneficial relationships between campus communities, contributions to the field of town-gown relations through academic research, and exemplary volunteer efforts that contribute to the quality of life of campus communities.

The continuing efforts and successes of Near West Side Partners can be seen online.

\section{Community Engagement}

Historically, community engagement has been an emphasis and source of pride for Marquette. President Lovell's three predecessors, Rev. Albert DiUlio, Rev. Robert Wild, and Rev. Scott Pilarz, had each during their tenures placed special focus on the neighborhood dating back to the early 1990s.

In 2015, Marquette received the Carnegie Classification for Higher Education Community Engagement and knew the time was right to leverage our success with Near West Side Partners to further elevate and prioritize community engagement efforts. We had many programs and projects under way that year. Marquette University faculty and staff received \$9.9 million in grants through corporate, foundation, state, and federal programs to conduct community-engaged research and provide service to address community-based issues. Beyond these external resources, our university was investing more than $\$ 17$ million worth of care and services annually in the city through its centers, clinics (dental, legal and health), institutes, and programs. Over $80 \%$ of our students participate in service during their undergraduate experience, and every school and college on campus provides their students with service-learning opportunities. Despite community engagement being a priority for our campus, it was clear that our universitywide understanding and coordination of it was lacking. From 2014-2015, three separate university task forces or committees, the Community Engagement Task Force, Academic Senate Committee on Diversity and Equity, and the President's Task Force on Diversity and Inclusion, 
all recommended the creation of a campus-wide and cohesive community engagement office. For this purpose, the Office of Community Engagement was launched in January 2016.

The Office of Community Engagement was strategically housed in the Office of the Provost to serve as a central clearinghouse for community engagement activities and to promote the scholarship of engagement. The office collaborates with partners across the institution, including the Office of Research and Innovation, deans, department chairs, faculty members, the Center for Teaching and Learning-Service Learning Program, the Center for Community Service, and the Offices of Student Affairs, Marketing and Communication, and Public Affairs, to ensure engagement efforts are effectively responding to the needs of the community while meeting the educational and research mission of the university. Over the first two years, with leadership from Daniel Bergen, Executive Director of the Office of Community Engagement, Marquette received nine local, state, and national awards for community engagement, including recognition as one of five institutions honored nationally by the Washington Center with a 2016 Higher Education Civic Engagement Award. Beyond elevating our profile, we began hosting Wisconsin's largest community engagement symposium, annually attracting over 300 participants for the one-day event; we have recruited community engaged scholars across disciplines, including psychology, education, nursing, exercise science, history, sociology, and communications.

In the winter of 2018, the Office of Community Engagement launched a new grant program (the President's Challenge) in partnership with the Johnson Controls Foundation. The challenge provides a $\$ 250,000$, two-year grant for one interdisciplinary, collaborative proposal that seeks to change the trajectory of lives in our community. Proposals required a diverse group of faculty members from the hard sciences, social sciences, and the humanities, to partner with Milwaukee community neighborhood organizations. Proposals needed to address one or more of the critical areas in which neighborhood inequities exist, including health, education, safety, housing, transportation, and/or economic prosperity. In January 2019, Marquette announced the first winner of the President's Challenge: the Next Step Clinic. The project will address critical mental health needs for central-city children and its team includes 10 Marquette faculty members, two African-American churches, and four other neighborhood organizations. More information about it is available online.

Building on the initial successes of the Office of Community Engagement, Marquette's provost convened a Community Engagement Task Force 2.0 in July of 2018. The task force brought together internal leaders, external partners, and faculty, staff, and students to seek

recommendations on how to further institutionalize community engagement. The goal of the task force was to establish Marquette as a forward-looking leader locally, nationally, and globally. Nearly 70 members of the Marquette community volunteered to be part of the task force and self-selected to serve among six working groups that were focused on dimensions of engagement: faculty/staff engagement, student engagement, profile and membership, mission, partnership management and cultivation, and impact/assessment. In each of their respective work groups, the teams were asked to produce SWOT (strengths, weakness, opportunities, threats) analyses, identify best practices, and create recommendations.

Their recommendations focused on policies, organizational structure, and staffing. One of the key recommendations was the addition of community-engaged research and teaching in the 
university's promotion and tenure guidelines. They reasoned such a concept is critical to the continued advancement of community engagement in research, teaching, and scholarship, the intentional recruitment of community-engaged scholars, and the ongoing support of current community-engaged faculty. Under the guidance of the senior vice provost, a promotion and tenure evaluation committee was formed. The committee included the executive director of community engagement, the vice president of corporate engagement, and several faculty members, and they will propose changes to tenure standards in spring 2020.

\section{Corporate Engagement}

Without significant engagement with our local corporate community, it would be impossible to fully implement "Beyond Boundaries," Marquette University's strategic plan. One challenge to our efforts was that we had poor cross campus communication regarding how best to approach our corporate partners. In addition, those approaches often had conflicting priorities and incentives. Corporate relationships often were overly reliant on an individual rather than a university structure and Marquette didn't have a centralized organizational effort to leverage.

To improve our corporate engagement efforts, a President's Task Force was formally launched in summer 2017. The task force was charged with evaluating current internal efforts through a SWOT analysis and determining best practices in corporate engagement at universities across the country. More than 80 individuals from campus and 10 existing corporate partners volunteered to take part in the task force. Each task force member joined a working team in one of the seven dimensions of corporate engagement: (a) Academic Programs and Executive Education; (b) Talent Development; (c) Corporate-Sponsored Research; (d) Technology Transfer; (e) Consortia and Alliances; (f) Corporate Philanthropy and Sponsorship; or (g) Contracts and Service Partnerships. Each team worked on an accelerated, six-month timeline to make formal recommendations as to how the university should move its corporate engagement efforts forward.

The numerous recommendations were evaluated and prioritized by the task force. Related to process and policies, the following seven recommendations were deemed the highest priority:

- Creating a single access point (web portal) and a central database to track all corporate interactions;

- Clearly recognizing corporate engagement as a contributor to tenure and promotion;

- Significantly improving career counseling services uniformly for all colleges/schools;

- Creating a customer relations management (CRM) tool;

- Developing streamlined intellectual property and technology transfer policies;

- Providing a mechanism to efficiently approve innovative corporate grants, contracts and partnerships; and

- Creating a model and infrastructure for effective communication across campus.

A key feature of the "single access point" included the creation of a new Office of Corporate Engagement and Partnerships (OCEP) to be led by a vice president reporting directly to the president. Earlier this year, Maura Donovan was named Vice President of Corporate Engagement at Marquette. Under her leadership, the OCEP has formalized, enhanced, and streamlined the 
ways in which Marquette works with corporate partners through communication, prioritization, consistency, and process excellence.

In 2018, just a few months after the Office of Corporate Engagement and Partnerships was formed, OCEP announced its first major corporate partnership with Town Bank for commercial and retail banking. Through the partnership, Town Bank (the Milwaukee-area branch of Wintrust Community Bank) sponsored Marquette Athletics and provided several million dollars in scholarship support for high-need students. Another initial success of the OCEP was the creation of a Data Science Institute with Northwestern Mutual and the University of WisconsinMilwaukee in June 2018. The institute, which was a joint investment of more than $\$ 40$ million, is physically housed in the Cream City Labs on Northwestern Mutual's Milwaukee campus where students, faculty, and Northwestern Mutual staff interact daily on research and educational programs. The institute grew out of a desire by Northwestern Mutual to not just improve its own abilities to extract value from digital information, but to transform southeastern Wisconsin into a region that prospers in the digital age by creating a healthy technology ecosystem in tandem with the region's two largest universities.

\section{Conclusion}

Our successes to better serve our region over the past five years have often overlapped with the task force processes in which we have engaged to address our most significant challenges. As is often the case in this fast-changing world, change does not wait. Sometimes we were addressing our problems before our task force process had clearly defined them. Near West Side Partners overlapped with the work of our community engagement task force, and it wasn't the only overlap with this task force. Another was Marquette's creation of the President's Challenge, identified earlier under the Community Engagement section. A third overlap was the university's involvement with hundreds of other people in Scaling Wellness in Milwaukee (SWIM) - a collaboration within the human services, healthcare, educational, and criminal justice sectors, that is bringing Wisconsin to the forefront of the trauma-informed care movement.

Throughout the task force processes for both corporate and community engagement, as well as within our efforts at advancing research partnerships in the Near West Side, the challenge of involving faculty in these areas consistently arose. Specifically, how do we reconfigure our guidelines that traditionally focus on academic publications as a primary factor for granting promotion and tenure to appropriately account for corporate and community engagement? That's a challenge ahead.

Considering the future, we can often look to our past. In the book, Universities and Their Cities: Urban Higher Education in America (2017), Marquette is featured at moments throughout. One particular quote from our past provides a guidepost for our future:

“On Marquette University's twenty-fifth anniversary, in 1906, when it was relatively small but on the verge of acquiring local law and medical schools and establishing its Department of Science and Engineering and School of Business Administration, the archbishop declared that 'what a state university does for Madison, a university located here would do for Milwaukee.’ Albert Fox, S.J., Marquette president from 1922-1928, 
promoted the institution as 'Milwaukee's University.' In an essay entitled 'University's Vision of a City,' he argued that a first-rate university needed an extensive partnership with its home city." (Diner 2017)

In other words, we're still working toward that extensive partnership with our home city that Rev. Fox wrote about nearly a century ago. However, we've come a long way, especially during these past five years. With better organization and better processes in place, we have every confidence we'll further carry on the mission started by St. Ignatius and his colleagues to create Catholic, Jesuit universities that produce citizens who live their lives in service to others. 